\title{
The Enabling Effects of Open Government Data on Collaborative Governance in Smart City Contexts
}

\author{
Martin Bartenberger*, Verena Grubmüller-Régent** \\ *Vienna University of Economics and Business; ** University of Applied Sciences Vienna
}

\begin{abstract}
The term "smart city" has been strongly promoted since the late 1990s, yet its concrete meaning remains blurry. In this article, we shed light on two elements that many "smart cities" claim to integrate: open data and collaborative/participatory governance. Notably, we investigate whether the common claim in the smart city literature that open data can promote more participative and collaborative forms of governance passes the test of additional theoretical interrogation. We criticize that while this literature has noticed the importance of participation and collaboration, the meaning of the concepts has remained vague. Therefore, we introduce a concrete yet comprehensive framework of collaborative governance from which we derive three theoretical assumptions regarding the potential influence of open data on collaborative processes in a smart city context: overcoming knowledge asymmetries, facilitating joint fact finding and enabling trust building. We conclude by outlining how our theoretical framework could guide further empirical research on the exact relation of smart cities, collaborative governance and open government data..
\end{abstract}

Keywords: Smart city governance, collaborative governance, participation, open government data, the city of Chicago

\section{Introduction}

The idea of "smart city" has been strongly promoted over the past decades. Especially in Europe, but also in the U.S., several cities have been labelled "smart" and compete in global and regional smart city rankings every year. While the term is widely used in politics and academia, its meanings and definitions are manifold. There are common elements in most definitions though, such as the reference to open (government) data and collaborative/participatory governance as crucial elements of smart cities, the general notion being that governments interact with citizens in a more open and transparent way as well as increasing possibilities for participation and collaboration. Yet, the exact relation between the three terms - smart city, open government data and collaborative governance - is blurry in many ways, and it remains unclear how they interact with and enhance one another.

In this article, we look at smart city governance with the aim to investigate mutual effects between open government data and collaborative governance processes. In section 2, we evaluate some of the most common smart city definitions and find both open (government) data and collaborative/participatory governance to be an integral part of most of these definitions. At the same time both of these terms remain highly vague and can vary in scope and meaning. We therefore introduce a smart city model as well as a precise framework of collaborative governance in section 3. Interpreting and exploring this framework in the context of smart cities and open data in section 4, we identify three concrete areas where open government data might help to promote collaborative governance in smart cities: to overcome knowledge asymmetries, to facilitate joint fact finding and to enable trust building. In section 5 we show how our theoretical framework could be able to guide further empirical research by briefly illustrating its application to the case of the Chicago Alternative Policing Strategy (CAPS). 


\section{Definition of Terms}

\subsection{Smart Cities and Open Government Data}

Since the late nineties, the term "smart city" has been used in numerous studies in different contexts. Accordingly, the definitions are manifold. Whilst originally referring to the "smart growth movement", the role of information and communication technologies (ICT) and their integration in urban processes has been highlighted as of 2005, notably by global ICT players such as CISCO, Siemens or IBM (Harrison, Donnely 2011, quoted in Ferro et al. 2013). More recent definitions of "smart city", in turn, tend to focus on the social and human aspect, pointing out the role of education and participation (e.g. Chourabi et al., 2012) while some of them are also referring to governance (e.g. Johnston, Hansen 2011). In accordance with Ferro et al. (2013), we are relying on a smart city definition covering all relevant aspects of this paper: "A city is smart when investments in human and social capital and traditional (transport) and modern (ICT) communication infrastructure fuel sustainable economic growth and a high quality of life, with a wise management of natural resources, through participatory governance" (Caragliu, Del Bo, Nijkamp, 2009).

In practice, moving towards a "smart city" means for city administrators to undergo "a longer process of technology-driven public sector reform" (Ferro et al., 2013). Even though nowadays, several (esp. European) cities qualify as smart cities according to different definitions (e.g. Cohen, 2014), a first desk research shows that some of them find it hard to reach the right balance in the ICT/social-human/governance triangle. Many of these cities are indeed very strong on the ICT-side, quickly integrating new technologies and technological trends, which do not, however, automatically generate social value such as participation. This is particularly obvious when it comes to the open data-trend, which has been picked up by a number of "smart" cities and - together with networks, software and according innovation-friendly legal standards - can be considered part of the fundament of smart city governance (see Figure 1). From this perspective, and in line with Lock and Sommerville (2010), the open accessibility of data is embedded in a "socio-technical infrastructure" and belongs to the "contextual factors that need to be present in an ecosystem in order for it to be able to fully exploit the potential of ICT" (Ferro et al., 2013). As the illustration in Figure 1 highlights, this social-technical infrastructure - with open data being one of its main elements - is the fundament of the "Smart City House" (ibid.) and a necessary precondition both for the contributions of ICT and the outcomes of social value.

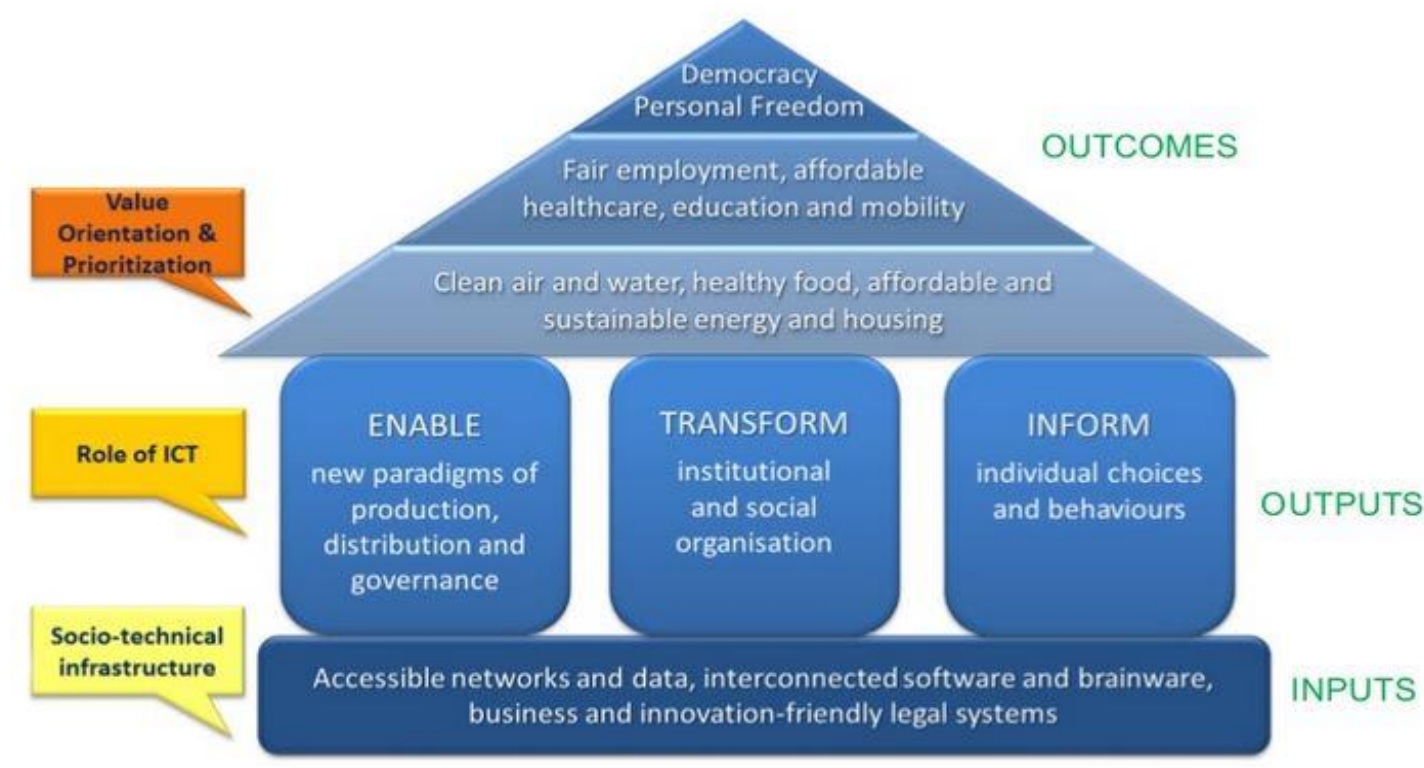

Figure 1 ICT in smart cities governance, Source: Ferro et al. 2013 
We are therefore focusing on open data as being one brick in the fundaments of the "Smart City House". As regards the definition of "open data", however, it is crucial to note that in spite of its widespread use, there is no common understanding as to the type of data (raw data versus processed or aggregated data), topical foci (e.g. traffic/mobility/accident data, health data, etc.) or the target group of this data (citizens generally, businesses, web-developers, NGOs, etc.). Due to this broad definition, numerous urban initiatives labelled "open data" can be found, which differ in all of these aspects but share the characteristics of an information source that is meant to serve the broader public. In the governmental context, this indicates that parts of government data shall be made freely accessible to citizens (Kuhn, 2014) - an aspect that is often discussed under the label "open government" and "government as a platform" (O'Reilly, 2011). Yet, the concepts of "open data" and "open government" are not interchangeable, but in general, the first is the precondition for the latter: Citizens shall be given the possibility to contribute to government initiatives and to interact with the public sector, which requires sufficient information, e.g. through open data (e.g. Chan, 2013). For pointing out this interrelation, we are using the term "open government data" in this article for open data published by public agencies or governments.

In terms of the "Smart City House" as introduced above, open government data is at the foundation of the house and therefore form an input from government side. The participation and collaboration of citizens on the other hand is a possible new paradigm of governance that can be enabled by open government data. It is therefore part of the first pillar of the model and thus marks a possible output of smart cities. Building on these two levels, the final outcomes of smart city governance should follow the broad values of democracy and personal freedom that constitute the top of the model by Ferro et al. (2013).

It is essential to note here that in the smart city context, the two terms of participation and collaboration are often used synonymously, described as a process that "allows members of the public to contribute ideas and expertise so that government can make policies with the benefit of information that is widely dispersed in society" (Jetzek et al., 2013). Accordingly, the concept of "new paradigms of governance" that Ferro et al. (2013) expect to arise out of the socio-technical infrastructure (including open government data) remains largely vague and unspecified. Their general way of thought is that open (government) data could enable forms of collaborative and participative governance since in order for citizens to participate in public projects or to voice their opinions, they first need to learn about the addressed issue and also need to have a platform where they can share their contributions. From this perspective open data can serve both to lower the barriers for participation and collaboration and to make citizen involvement more attractive (Jetzek et al., 2013).

\subsection{Smart Cities and Collaborative Governance}

We share the general notion that open government data might enable new and more participative and collaborative forms of governance as it has been voiced by many scholars in the field (Ferro et al., 2013; Jetzek et al., 2013; O'Reilly, 2011). However, we find this assumption far too general and often based on a rather imprecise understanding of collaborative and participative forms of governance. Therefore - and in contrast to what can commonly be found in the smart city context we distinguish the two aspects of participation and collaboration from one another and introduce a specific and well-defined concept of such new form of governance. In doing so, we build on a distinct body of literature which has evolved in political science and public administration over the last decades that centers around the term "collaborative governance" (see Ansell, 2012 for a good overview).

Broadly speaking, this literature focuses on how the collaboration of governments and public agencies with non-state actors can be described as a novel and innovative form of governance. We argue that this discussion on collaborative governance goes a decisive step further than a focus on participatory approaches. Participation merely implies that non-state actors, such as citizens or NGOs, are heard and have some role in the decision-making process. But their exact role in the 
process is not further specified and can range from being a spectator over expressing preferences to having veto capacities in the decision making process (Fung, 2006). In other words, when using the term participation, it is not granted that non-state actors are really able to influence decisions and play an active role in the process. Collaboration, in contrast, implies a much more active inclusion of non-state actors that goes beyond the scope of solely observing or commenting on decisions that are made by public agencies.

In defining collaborative governance we follow Ansell's and Gash's approach (2008, p. 544), who provide a comprehensive overview of the literature and arrive at the following definition of collaborative governance: „A governing arrangement where one or more public agencies directly engage non-state stakeholders in a collective decision-making process that is formal, consensusoriented, and deliberative and that aims to make or implement public policy or manage public programs or assets. "We choose this definition because it offers a precise description of the term that clearly separates it from the broader concept of participatory democracy. Collaborative governance in this more restrictive sense focuses on approaches where public agencies initiate a joint decision-making process with non-state actors to reach a consensus-based solution for a concrete public policy problem. Non-state actors are therefore able not only to observe public decision-making processes or express their opinion on its outcomes but play an active and equal role in it. Collaborative governance in this sense is also much more than the simple collaboration of different public agencies and bureaucracies (Huxham, Vangen, Huxham \& Eden, 2000) but requires the active involvement of non-state actors.

As Huxman and his colleagues (2000, p. 340) have highlighted, it is also important to note that collaborative governance not only entails an instrumental purpose, but also a normative dimension. As far as we can see, the underlying assumptions in many cases can be traced back to a pragmatist understanding of democracy (Ansell, 2011). Pragmatist accounts of democracy emphasize many of the same key assumptions that are also present in the concept of collaborative governance: First, both share the argument that the public is capable of solving societal problems and should not only rely on elected officials and experts, but be actively involved in this problem-solving process (Dewey, 1927; Gatens-Robinson, 1999). Second, this problem-centered process itself is seen as an important way to fruitfully engage in conflicts. In this context, pragmatists highlight how „, a focus on the 'problem' redirects attention away from the symptoms of conflict per se (e.g. dislike or distrust of rival parties) toward its deeper causes" (Ansell, 2011, 169). Third, from both a pragmatist and a collaborative governance perspective, this joint process of creative problem-solving will eventually lead to mutual social learning. Ideally it does so „by reframing the basic relationship among stakeholders away from a contest of rival goals and preferences towards a position of shared uncertainty. Where stakeholders can find a ground of shared uncertainty, they will discover common ground for a provisional stance toward problem solving" (ibid., p. 174).

While the literature on smart cities has noticed the importance of participation and collaboration, the meaning of the concepts has remained vague. We want to take the debate a step further by sharpening the underlying ideas and assess the role that collaboration plays in smart cities. We do so by concentrating on the claim that open government data might be able to advance a new form of governance, in our case in the well-defined form of collaborative governance as it will be introduced in the next section. Building on our specific framework of collaborative governance we explore this claim further and address the following research question: In which ways can the open government data initiatives of smart cities promote and advance collaborative governance?

\footnotetext{
${ }^{1}$ Alternative approaches to establish frameworks or models of collaborative governance have notably been made by Emerson, Nabatchi and Balogh (2012) and Sirianni (2009).
} 


\section{A Model of Collaborative Governance}

Building on their definition as outlined above, Ansell and Gash have developed a model of collaborative governance (see Figure 2) where they stress the importance of certain starting conditions that can either facilitate or discourage collaboration of state and non-state actors. This could be the prehistory that exists between the involved stakeholders already and that influences the initial trust level, but also certain incentives and constraints that are present in the concerned institutions and organisations. A third important starting condition that influences the possibility of collaborative governance is defined by asymmetries in power, resources and knowledge. As Ansell and Gash note, this problem of asymmetries is especially important: „If some stakeholders do not have the capacity, organization, status, or resources to participate, or to participate on an equal footing with other stakeholders, the collaborative governance process will be prone to manipulation by stronger actors" (Ansell \& Gash, 2008, p. 551). ${ }^{2}$

Accordingly, when it comes to the collaborative process itself, the model by Ansell and Gash puts a special emphasis on the role of trust, commitment and shared understanding. Key to this is a continuous face-to-face dialogue and a focus on intermediate outcomes such as "small wins". On the other hand the process of collaboration is also crucially influenced by institutional design and leadership. When designing the institutions of collaboration, stakeholders should actively seek internal inclusiveness (include all relevant stakeholders), external exclusiveness (no other similar forums of collaboration in the area) and lay down clear and transparent process rules (Ansell \& Gash, 2008 , p. 556). In this institutional context, leaders play a significant role that can range from being stewards (manage collaboration and process integrity), mediators (manage conflicts) or catalysts (identify and realize opportunities) (Ansell \& Gash, 2012).

\footnotetext{
${ }^{2}$ We will see in the next section how open government data might be useful in overcoming existing asymmetries of knowledge and information.
} 


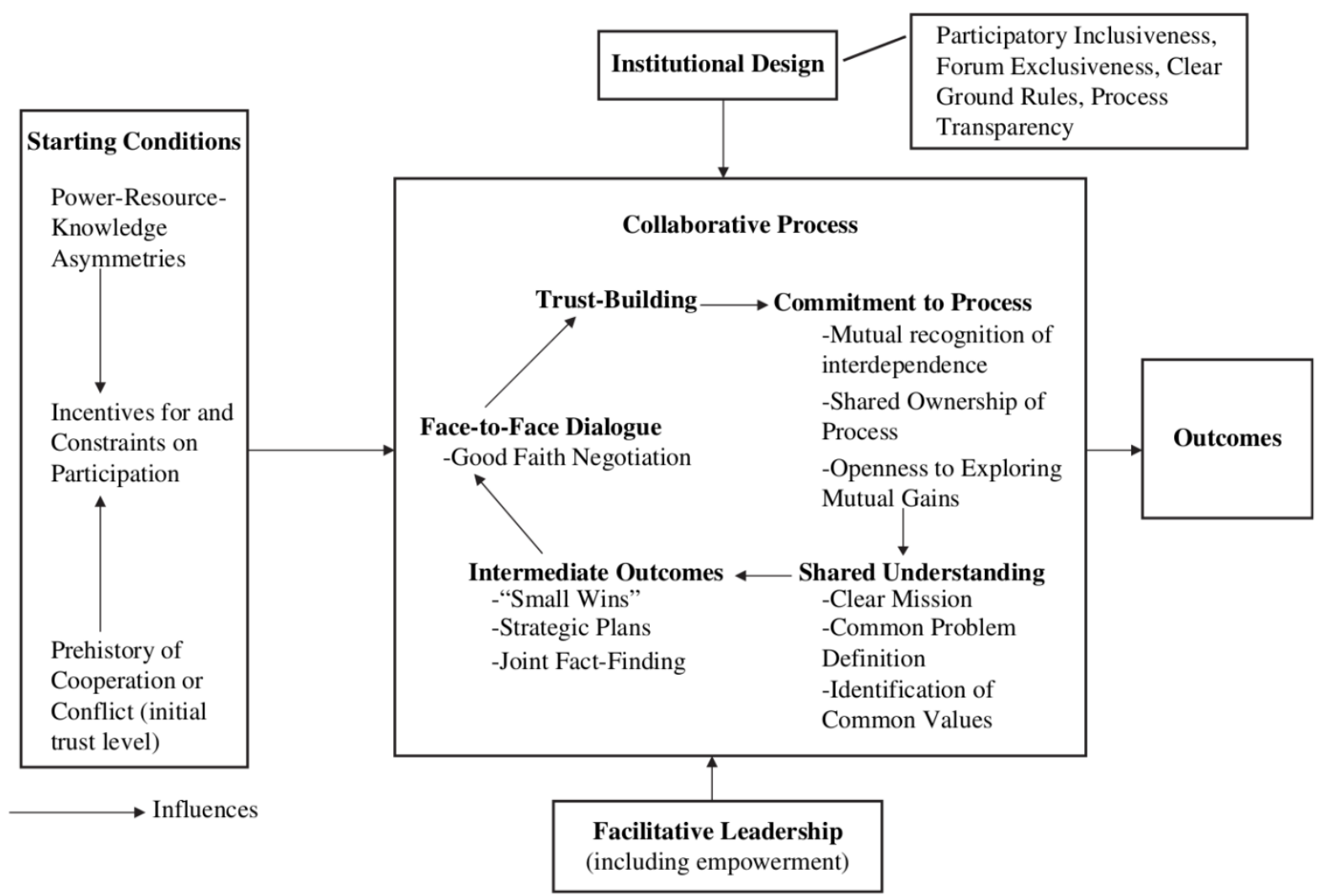

Figure 2 A model of collaborative governance, Source: Ansell \& Gash, 2008.

To conclude, it is important to note that this model of collaborative governance should not be regarded as a comprehensive illustration of its causal processes. Instead as a "contingency model" (Ansell \& Gash, 2008, p. 550), it aims to identify and organize the most important conditions and aspects of collaborative governance that can determine its success or failure. The model highlights that collaborative governance is a complex process that relies on different conditions, institutional settings and contextual variables. It is a process that requires time, building of trust and generation of a sense of interdependence between the involved stakeholders (ibid., p. 561). But if it is successful, it promises not only better and more inclusive policy outcomes but also the long-term ability to „transform adversarial relationships into more cooperative ones“ (ibid., 547).

\section{Open Government Data in Collaborative Governance}

Building on the works by Ansell and Gash, we extend their model of collaborative governance as introduced in the previous section and ask how and where open government data could help to enable, promote and support collaborative governance. We propose that there are especially three elements where collaborative governance can benefit from open government data: overcoming knowledge asymmetries, facilitating joint fact finding and enabling trust building. We develop a theoretical assumption for each of the three aspects and invite further empirical research on them in the final part of our article. 


\subsection{Overcoming Knowledge Asymmetries}

In the process of collaboration, knowledge plays a crucial role (see Agranoff, 2006). Kirk Emerson and his colleagues have even gone so far to call knowledge "the currency of collaboration" (Emerson, Nabatchi, \& Balogh, 2012, p. 16). In the model offered by Ansell and Gash, asymmetries of power, resources and knowledge are therefore identified as important constraints that can hinder collaborative governance. Under these conditions, stakeholders will be skeptical about participating in collaborative processes together with actors that trump them in terms of resources, knowledge and organisational power (Ansell \& Gash 2008, p. 551).

We argue that the usage of open government data in collaborative governance could target this problem, decrease knowledge asymmetries and thereby level the playing field. This could mean for example that a city administration releases data sets that are relevant for a certain forum of collaborative governance on their open data portal. Knowledge that before was only available to a certain group of stakeholders (e.g. public agencies) is now made available for non-state stakeholders as well. Our claim that open government data could decrease knowledge asymmetries is underlined by the fact that open government data has widely been heralded as a way to broaden the access to knowledge and information. It is essential to note though that open data does not equal knowledge. As Agranoff (2006, p. 60) has highlighted: „Whereas data refer to discrete, objective facts, and information is a message in the form of a document or an audible or visual communication, knowledge is more action oriented, both in process and in outcome".

This is a point that has also been taken up in the debate on open data and led to discussions about the term itself. Does open data refer to the raw data sets or only to their aggregated and organised form? Following Agranoff's remarks it would not be sufficient to release data as pure data (e.g. in the form of spreadsheets or XML files). Instead, he claims that data needs to be organised and made accessible in a way that transforms pure data into knowledge. At the same time, others have referred to the advantages of raw data, since it can be made available without any major time delay (e.g. Government of Canada 2014). However, this would delimit (certain) citizens' access to this data for reasons of lacking skills in handling raw data.

Taking this discussion into account the World Wide Web Consortium (W3C) makes several recommendations in their guidelines for the publication of open government data, including the documentation of published data sets, the preservation of older data and the creation of open interfaces (W3C, 2009). All these steps are meant to lead from an outset where the data is simply machine-readable to a stage where it is also human-readable, i.e. presented and organised in a form that allows citizens to explore and understand the data at hand. In the words of Agraboff (2006), the recommendations by the $\mathrm{W} 3 \mathrm{C}$ describe a process that allows transforming open data into open knowledge. We therefore identify this process as a necessary condition for the relevance of open data in collaborative governance. This leads us to our first assumption concerning open government data and knowledge asymmetries:

Assumption 1: Open government data that is presented in a human-readable form can decrease knowledge asymmetries between state and non-state actors and thereby help to promote collaborative governance.

\subsection{Facilitating Joint Fact Finding}

In highlighting the importance of joint fact finding in their model of collaborative governance, Ansell and Gash can build on various other authors who have similarly emphasized how joint exploration and knowledge-generation can foster collaboration among state and non-state stakeholders. Saarikoski for instance examined how joint fact finding has played an important role in collectively generating a new waste management strategy in Finland: „Joint fact finding did contribute to a shared understanding of some of the potential impacts of the waste management alternatives. The parties came to see that, contrary to their previous assumptions, neither incineration nor recycling is unambiguously more energy efficient, but that the net energy balance depends on the recovery rate" (Saarikoski, 2000, p. 691). Additionally Karl and his colleagues (2007, p. 23) have shown that since 
joint fact finding „promotes shared learning, it helps to create knowledge that is technically credible, publicly legitimate, and especially relevant to policy and management decisions".

On the other hand, in evaluating cases of collaborative water governance in South Australia, Taylor et al. have found that "the cases examined in this research achieved successful outcomes related to knowledge production despite the fact that the collaborative processes fell short of joint fact-finding and authentic dialogue" (Taylor, de Loë \& Bjornlund, 2012, p. 62). They especially criticized how "time pressures and inadequate discussion of technical information“ (ibid., p. 56) have hindered joint fact finding and the inclusion of all relevant stakeholders.

We argue that open government data could support joint fact finding by providing shared knowledge bases and accepted sources of information that can be used and accessed by all stakeholders. Publishing relevant materials as open data could also help to reduce the problem of time pressure as identified by Taylor et al. (2012) since it is one of the core principles of open government data that it should be released as promptly as necessary. ${ }^{3}$ The fact that data can be released in advance would not only give the stakeholders of the joint fact finding mission more time to explore the relevant material but would also enable external experts to support this process. Software developers could come up with intuitive ways to organize and understand the material while other experts could provide additional interpretations and explanations (Robinson, Yu, Zeller, \& Felten, 2009). We therefore arrive at our second assumption concerning open government data and joint fact finding:

Assumption 2: Open government data can facilitate joint fact finding in collaborative governance by offering shared knowledge bases and accepted sources of information.

\subsection{Enabling Trust Building}

The final aspect of collaborative governance where we see potential for open government data is trust building. Trust is one of the main pillars of collaborative governance that is mentioned throughout the literature (e.g. Emerson, Nabatchi, \& Balogh, 2012; Huxham et al., 2000; Leach \& Sabatier, 2005). Trust building is an integral part of Ansell and Gash's model of collaborative governance for instance, who found that it "often becomes the most prominent aspect of the early collaborative process and can be quite difficult to cultivate" (Ansell \& Gash, 2008, p. 558). This goes back to the fact that the involved stakeholders have to act in good faith in order for collaborative governance to be possible and eventually successful: „Leaders are asking stakeholders to engage in good faith negotiation and to explore possibilities for compromise and mutual gains. But stakeholders often enter into the collaborative process in a skeptical frame of mind. They are sensitive to issues of equity, concerned about the power of other stakeholders, and alive to the possibility of being manipulated" (ibid., p. 557).

Among the measures that can increase trust and understanding is the important role of face-toface communication (Leach \& Sabatier, 2005) and the emphasis on the mutual interdependence of the involved stakeholders (Ansell \& Gash, 2008). In this context, we argue that open government data could be an additional factor that promotes mutual trust and understanding especially on a symbolic level. By making parts of their knowledge available to all stakeholders and the public as open data, state actors can show that they have nothing to hide and are willing to commit to the process of collaboration. They can also signal non-state stakeholders that they are willing to decrease knowledge asymmetries while at the same time promoting transparency and inclusiveness (for an excellent study on this topic see Rojas, 2012).

\footnotetext{
${ }^{3}$ The idea that open data should be released "timely" has become to be known as one of the eight principles of open government data (Tauberer, 2012). It has also been taken up in a memorandum by the White House in 2013 which states: „Open data are made available as quickly as necessary to preserve the value of the data. Frequency of release should account for key audiences and downstream needs" (Executive Office of the President, 2013).
} 
We argue that it is the sheer willingness to make information available that can foster trust on a symbolic level. Saarikoski mentions an example from Finland that illustrates our point. There, people had to collaborate to agree on a new waste management strategy and compare different Life Cycle Assessments (LCAs) which were made available to the participants. This led to a situation where „participants had a chance to check the assumptions and steps of the LCA themselves. As one participant mentioned in the interview, he did not read all the background material about LCAs because it was so detailed, but the fact that the information was there made the analysis seem more reliable" (Saarikoski, 2000, p. 691). From our perspective this is an excellent example how the fact that information was published and made transparent led to greater trust in the process, no matter if the available material was actually read by participants or not. It is therefore a primarily symbolic mechanism that is at work here, where not the data as such is essential, but its availability and the symbolic act of publishing that signals the honesty and commitment of state actors and increases trust among non-state actors. Evaluating the potential of open government data for trust building we arrive at our final assumption:

Assumption 3: Open government data can enable trust building by symbolically attesting the commitment of state actors to the process of collaboration.

\section{Guidelines for Empirical Research}

Having assessed the theoretical concept of collaborative governance, we will now provide some preliminary ideas on how further empirical research could be conducted in the field of smart cities, collaborative governance and open government data. In the first part of this paper we began by introducing the concept of the "Smart City House" by Ferro et al. (2013), which demonstrates how both collaborative governance and open government data play an integral part in ideas of smart cities. From this model and other works on smart cities we have derived a general yet unspecific claim that open data hold the potential to enable new and more democratic forms of governance. We have examined this claim in greater detail by introducing a specific understanding of such a new governance paradigm in the form of the collaborative governance framework by Ansell and Gash (2008). Having analysed the relation of collaborative governance and open government data further and summing up our conclusions from the previous section, we now can assume that the general claim can be specified along the three following assumptions: open government data might (1) decrease knowledge asymmetries, (2) offer shared knowledge bases and accepted sources of information, and therefore (3) enable trust building.

Having specified the claim of the smart city literature that open data can lead to new forms of more collaborative and participative governance we suggest that our framework and the three assumptions we have derived from it should be put to the test of empirical research. By examining cases of "smart cities" with existing open government data portals such research could illuminate the question if our three assumptions are correct and if cases exist that document the enabling effects of open government data for collaborative governance. We provide some guidance for such empirical research by briefly introducing an example from the literature of collaborative governance that might have witnessed some enabling effects of open government data already.

\subsection{The Chicago Alternative Policing Strategy and Possible Effects of Open Government Data}

When it comes to collaborative governance, the City of Chicago has a prominent example to offer which has been discussed extensively in the literature on collaborative governance and deliberative democracy (Fung, 2001, 2009; Ansell, 2011): the Chicago Alternative Policing Strategy (CAPS). CAPS started in 1993 and implemented an approach of community policing that began with a simple assumption: "if police, residents and other City agencies work together, they can reduce crime" (Chicago Police Department, 1998, p.5). Building on the principles of "public involvement, problemsolving and agency partnerships" (Chicago Police Department, 2003, p.2) the program tried to improve the situation in a city dramatically stricken by gun violence and drug crime. To accomplish this, Chicago was divided into many small police beats, each with a group of dedicated police officers 
that were familiar with the neighborhoods and responsible to reduce crime in the area. These teams hold regular beat meetings each month and invite residents to discuss current problems and new ways to reduce crime in their districts together.

Twenty years after its beginning, the record of CAPS is mixed. While some have praised the innovative character of the program (Fung, 2001, 2009) its efficiency to reduce crime has been disputed by others (Dumke, 2011). This has led the new city administration under Rahm Emanuel to announce plans to restructure the program to combat violence better (Bowean, 2013). Whatever the merits of CAPS are, it remains clear that it is an important case of collaborative governance where a city administration collaborated with citizens and advocacy groups in order to improve police strategies together.

Given this prominent example of collaborative governance in Chicago, we explored if we can find indicators where open government data has helped to promote this process along the lines sketched out in the first part of the paper. This endeavor is supported by the fact that Chicago has released many of the data sets that are relevant to CAPS, such as crime statistics and dates of beat meeting as open government data on their data portal.

1. The first assumption stated that open government data can decrease knowledge asymmetries between state and non-state actors and thereby help to promote collaborative governance. Examining the CAPS example we find some evidence for this assumption in the form of the "CAPSure app". Using data that is regularly released by the Chicago Police Department, CAPSure helps users to find out about the next beat meetings that they can attend. Since participation of residents is crucial for the success of beat meetings and CAPS in general the usage of open government data for this purpose is highly relevant.

2. Regarding our second assumption we find some evidence for CAPS-related joint fact finding. As the Chicago Police Department highlights, it is at the center of each beat meetings that police officers present recent data on crime rates and the pressing problems of the beat (City of Chicago, n.d.). This should create an atmosphere of informed decision-making that does not rely solely on personal experiences and prioritizes visible crimes, but puts them in relation with statistical data on current crime conditions. Being in line with the idea of joint fact finding as introduced before, this should ensure that all participants "have a handle on the entire crime picture before [they] decide which specific problems to address" (Chicago Police Department, n.d.). Additional research would be necessary to exactly identify the role that open government data plays in this context but from what we know now we can assert that in this data-driven process there is immense practical potential for open government data.

3. For our third assumption, which indicated the positive impact that open government data could have on mutual trust-building in collaborative governance we find no hints that this could be the case in Chicago so far. Instead, if problems of trust have been identified to be a major hindrance for the success of CAPS, they have been largely related to the unresponsiveness of individual police officers or the Chicago Police Department as such (Bowean, 2013). This has led to frustration on the side of citizens who felt that their complaints and inputs are not taken seriously and have little effect to improve the situation in their neighborhoods. Whether the additional release of open government data could help to improve this situation will be shown over the next years. There are signs however, that the City of Chicago is aware of this problem. In its annual report on open data the city has pledged to expand its disclosure of 311 calls in 2014 (City of Chicago, 2014) which include the most common service requests by citizens. Using this data, citizens can track whether their request to fix potholes, to remove graffiti or an abandoned vehicle has been noticed and if it has been processed already. If a similar approach will be taken for crime related requests, the city could improve the sense among residents that their complaints are being heard and show how they inform the police strategy in their neighborhood. 


\section{Conclusion}

In this paper, we have focused on the aspects of open government data and collaborative governance as constitutional elements of "smart cities". In doing so, we looked at the numerous definitions of "smart cities", all of which are highly varied in terms of meaning and focus. Therefore, out of a rather fuzzy smart city concept, we limited our research to these two elements and thereby strongly focused on the inputs and outputs of a smart city model: open government data being among the inputs, collaborative governance processes among the possible outputs.

Thereby, we have highlighted more participative and collaborative forms of governance as an important element of smart cities, which led us to addressing the question whether smart cities that rely on open government data offer a suitable environment for enhancing these novel forms of governance. Here, we applied a very narrow definition of collaborative governance and clearly distinguished it from mere participation by the component of an active inclusion of non-state actors in actual decision making processes. In this regard, collaborative governance is meant to be going beyond mere observing or commenting on government decisions.

By going through the theoretical framework that underlies our understanding of collaborative governance, we could derive three assumptions about the potentials of open government data in enhancing collaborative governance in smart cities: first, if provided in a suitable manner, open data can help overcoming knowledge asymmetries by giving broad access to information and knowledge; second, it might be able to facilitate joint fact finding by offering shared knowledge bases and accepted sources of information; and third, it could enable trust building. Having said this, we highlighted how the way in which open data is provided plays a decisive role whether these assumptions hold true or not. For instance there is a difference whether raw or aggregated data is used when it comes to the skillset that is needed for reading, encoding and making use of this data. Also, even more fundamentally, it depends on the city's measures to foster what is commonly referred to as "elnclusion", meaning the reduction of the "digital divide" which hinders inclusive access to information and knowledge.

In the concluding sections of our paper we have encouraged empirical research to examine our three theoretical assumptions and test the model of collaborative governance and open government data that we have proposed. We have outlined possible ways to engage this task by briefly introducing the example of CAPS, where we have found some first evidence how open government data influences concrete settings of collaborative governance. With this brief example we hope to have provided a first real-world example on how open government data and collaborative governance interact as presupposed by our model. While the preliminary results there seem to be promising, more empirical research covering additional case studies in greater depth is highly needed in order to learn more about how open government data can enable collaborative governance.

\section{References}

Agranoff, R. (2006). Inside Collaborative Networks: Ten Lessons for Public Managers. Public Administration Review, 66, $56-65$.

Ansell, C. (2011). Pragmatist Democracy. Evolutionary Learning as Public Philosophy. Oxford: Oxford University Press.

Ansell, C. (2012). Collaborative Governance. In D. Levi-Faur (Ed.), The Oxford Handbook of Governance (pp. 498-511). Oxford: Oxford University Press.

Ansell, C., \& Gash, A. (2008). Collaborative Governance in Theory and Practice. Journal of Public Administration Research and Theory, 18(4), 543-571.

Ansell, C. K., \& Gash, A. (2012). Stewards, Mediators, and Catalysts: Toward a Model of Collaborative Leadership. The Innovation Journal: The Public Sector Innovation Journal, 17(1), 1-21.

Bowean, L. (2013). Chicago police look to revamp CAPS. Retrieved July 7, 2014, from articles.chicagotribune.com/201302-25/news/ct-met-caps-chicago-police-20130225_1_caps-program-chicago-police-fight-crime 
Chicago Police Department (n.d.). Become An Informed Decision-Maker and Problem-Solver portal.chicagopolice.org/portal/page/portal/ClearPath/Get\%20Involved/How\%20CAPS\%20works/InformedDecisionMaker

Chicago Police Department (1998). CAPS at 5. A Report on the Progress of Community Policing in Chicago. Retrieved July 7, 2014, from portal.chicagopolice.org/i/cpd/clearpath/CAPSat5.pdf

Chicago Police Department (2003). CAPS at Ten: Community Policing in Chicago. An Evaluation of Chicago's Alternative Policing Strategy. Retrieved July 7, 2014, from portal.chicagopolice.org/i/cpd/clearpath/Caps10.pdf

City of Chicago (n.d.). Getting The Most From Your Beat Meeting. Retrieved July 8, 2014 from portal.chicagopolice.org/i/cpd/clearpath/BtMtgPmphlt

City of Chicago (2014). Chicago Open Data Report 2013. Retrieved July 7, 2014, from github.com/Chicago/open-dataannual-report/blob/master/open-data-2013.pdf

Department for Business, Innovation and Skills (2013). Global Innovators: International Case Studies on Smart Cities. Retrieved July 7, 2014 from www.gov.uk/government/publications/smart-cities-international-case-studies-global-innovators

Caragliu, A., Del Bo, C., Nijkamp, P. (2009). Smart Cities in Europe. In Proceedings of the 3rd Central European Conference in Regional Science - CERS 2009 (pp. 49 - 59).

Chan, C. M. L. (2013, 7-10 Jan. 2013). From Open Data to Open Innovation Strategies: Creating E-Services Using Open Government Data. Paper presented at the System Sciences (HICSS), 2013 46th Hawaii International Conference

Chourabi, H., Nam, T., Walker, S., Gil-Garcia, J. R., Mellouli, S., Nahon, K., Pardo, T., Scholl, H.J. (2012): Understanding Smart Cities: An Integrative Framework. In Proceedings of 45th Hawaii International Conference on System Sciences

Cohen, B. (2014): The ten smartest Cities in Europe, URL: http://www.fastcoexist.com/3024721/the-10-smartest-cities-ineurope\#10 (dl July 21, 2014)

Dewey, J. (1927). The Public and Its Problems. New York: H. Holt and Company.

Dumke, M. (2011). Community Policing Is Caught in a Cross-Fire. Retrieved July 8, 2014, from www.nytimes.com/2011/01/09/us/09cnccommunity.html

Emerson, K., Nabatchi, T., \& Balogh, S. (2012). An Integrative Framework for Collaborative Governance. Journal of Public Administration Research and Theory, 22(1), 1-29.

Executive Office of the President (2013). M-13-13. Memorandum for the Heads of Executive Departments and Agencies. Retrieved July 26, 2014, from www.whitehouse.gov/sites/default/files/omb/memoranda/2013/m-13-13.pdf

Ferro, Enrico, Caroleo, Brunella, Leo, Maurizio, Osella, Michele, Pautasso, Elisa (2013): The Role of ICT in Smart Cities Governance, in: Parycek, Peter, Edelmann, Noella (eds.): CeDEM13. Proceedings of the International Conference for EDemocracy and Open Government, pp. 145 - 158

Fung, A. (2001). Accountable Autonomy: Toward Empowered Deliberation in Chicago Schools and Policing. Politics \& Society, 29(1), 73-103.

Fung, A. (2009). Empowered Participation: Reinventing Urban Democracy. Princeton: Princeton University Press.

Fung, A. (2006). Varieties of Participation in Complex Governance. Public Administration Review, 66, 66-75.

Gatens-Robinson, E. (1999). The Private and Its Problem: A Pragmatic View of Reproductive Choice. In C. Haskins \& D. I. Seiple (Eds.), Dewey Reconfigured: Essays on Deweyan Pragmatism (pp. 169-191). Albany, NY: State University of New York Press.

Government of Canada (2014): Open Data 101, URL: http://data.gc.ca/eng/open-data-101\#toc4 (dl July 28, 2014)

Harrison, C., Donnely, I. A., (2011). Theory of Smart Cities. In Proceedings of the 55th Annual Meeting of the ISSS

Huxham, C., Vangen, S., Huxham, C., \& Eden, C. (2000). The Challenge of Collaborative Governance. Public Management: An International Journal of Research and Theory, 2(3), 337-358.

Jetzek, T., Avital, M., Bjorn-Andersen, N. (2013): Generating Value from Open Government Data, in: Proceedings of Thirty Fourth International Conference on Information Systems, Milan 
Johnston, E.W., Hansen, D.L. (2011): Design lessons for smart governance infrastructures, in: D. Ink, A. Balutis, T.F. Buss (Eds.), Transforming American Governance: Rebooting the Public Square? New York: M. E. Sharpe

Karl, H. A., Susskind, L. E., \& Wallace, K. H. (2007). A Dialogue, not a Diatribe. Effective Integration of Science and Policy through Joint Fact Finding. Environment, 49(1), 20-34.

Kuhn, J. (2014) : Open Government : Who participates and why ? Master Thesis University of Berlin/University of Twente

Leach, W. D., \& Sabatier, P. A. (2005). To Trust an Adversary: Integrating Rational and Psychological Models of Collaborative Policymaking. American Political Science Review, 99(04), 491-503.

Lock, R., Sommerville, I. (2010) : Modelling and Analysis of Socio-Technical System of Systems. In Proceedings of the 15th IEEE International Conference on Engineering of Complex Computer Systems (pp. 224 - 232)

Newman, J., Barnes, M., Sullivan, H., \& Knops, A. (2004). Public Participation and Collaborative Governance. Journal of Social Policy, 33(2), 203-223.

O'Reilly, T. (2011). Government as a Platform. Innovations: Technology, Governance, Globalization, 6(1), 13-40.

Robinson, D., Yu, H., Zeller, W., \& Felten, E. (2009). Government Data and the Invisible Hand. Yale Journal of Law and Technology, 11(1), 160-175.

Rojas, F.M. (2012). Transit Transparency: Effective Disclosure through Open Data. Retrieved July 26, 2014, from www.transparencypolicy.net/assets/FINAL_UTC_TransitTransparency_8\%2028\%202012.pdf

Saarikoski, H. (2000). Environmental Impact Assessment (EIA) as Collaborative Learning Process. Environmental Impact Assessment Review, 20(6), 681-700.

Sirianni, C. (2009). Investing in Democracy: Engaging Citizens in Collaborative Governance. Washington D.C.: Brookings Institution Press.

Tauberer, J. (2012). Open Government Data. Retrieved July 27, 2014, from opengovdata.io

Taylor, B., de Loë, R. C., \& Bjornlund, H. (2013). Evaluating Knowledge Production and Use in Collaborative Water Governance. Water Alternatives, 6(1): 42-66.

W3C (2009). Publishing Open Government Data. W3C Working Draft 8 September 2009. Retrieved July 3, 2014, from www.w3.org/TR/gov-data

\section{About the Authors}

Martin Bartenberger is Research and Teaching Associate at the Institute for Public Management and Governance, Vienna University of Economics and Business. His research interests include collaborative governance, experimentalist modes of policymaking, media politics and political crisis management.

Verena Grubmüller-Régent., holds Master degrees in Sociology and Social Economics and a PhD from the Faculty of Social and Economic Sciences at the Johannes Kepler University of Linz, Austria. Her research focus is on international migration, different aspects of diversity and inclusion, the accessibility and usability of new technologies ("digital divide"), as well as Web2.0 technologies in eGovernance and social science research and their ethical and privacy aspects. 